\title{
PROPOSIÇÃO DE UM PROTOCOLO PARA AVALIAÇÃO DA ESTÉTICA NO DESIGN PARA SERVIÇOS
}

Humberto Costa

Universidade Federal do Paraná - UFPR

Centro Universitário Curitiba - Unicuritiba

humbertoccosta@gmail.com

Aguinaldo dos Santos

Universidade Federal do Paraná - UFPR

asantos@ufpr.br

Resumo: O presente artigo reporta-se aos resultados da pesquisa que trata do tema: o design para serviços e avaliação estética. $O$ problema central desta pesquisa é consubstanciado na questão: como manter a consistência estética em serviços prestados aos cidadãos? O objetivo é propor um protocolo de avaliação estética capaz de auxiliar na manutenção da consistência estética em serviços prestados aos cidadãos. Para a realização do estudo, foram utilizadas a revisão bibliográfica sistemática e uma abordagem de cunho etnográfico. A pesquisa de campo foi realizada em hospital público especializado em idosos. O protocolo proposto envolve três etapas: 1) "Preparação"; 2) "Caracterização da percepção estética do serviço"; 3) "Análise das informações", e foi capaz de mostrar a efetividade da integração da lógica SERVQUAL com as ferramentas utilizadas no âmbito do Design de Serviços. O resultado, ainda que preliminar, apresenta um protocolo de avaliação estética de serviços, que pode também ser utilizado para a manutenção da consistência estética do serviço analisado.

Palavras-chave: Avaliação estética de serviços, Estética em serviços, Consistência estética de serviços, Design para serviços, Serviços. 


\section{INTRODUÇÃO}

O setor de serviços gera a maior parcela do Produto Interno Bruto - PIB, das maiores economias do mundo (PINHANEZ, 2009) e é responsável por empregar a maior parcela de trabalhadores. No Brasil, o setor de serviços gera 69,4\% do PIB (IBGE, 2010) e emprega aproximadamente $60 \%$ da população ativa (OLIVEIRA Jr., 2015). Atualmente, os serviços ocupam cada vez mais a agenda de pesquisadores e empresas, interessados em desenvolver soluções orientadas ao desenvolvimento sustentável, tendo em vista a possibilidade de (parcialmente) desmaterializar o consumo de artefatos físicos (SANTOS et. al. 2014). De outro lado, constata-se a necessidade de profissionais aptos a atuar na área, assim como o estímulo à implantação de empresas com especialidade no tema (SANTOS \& COSTA, 2014). Um dos gargalos para contemplar tal demanda é a existência de ferramentas e métodos específicos para 0 contexto do processo de Design de Serviços ('D.S'), validadas dentro do contexto brasileiro. Dentre estes gargalos, o presente artigo trata da dimensão estética do processo de 'D.S'. Autores como Freire (2011) e Candi \& Saemundsson (2011), também apontam a dimensão estética como uma temática que requer avanços no conhecimento por parte da comunidade de pesquisa em Design.

Adotou-se a acepção grega do termo estética, o qual denota sensação, sentimento, estesia. Entende-se que é tarefa da estética analisar os complexos das sensações e dos sentimentos humanos, investigando a "sua integração nas atividades físicas e mentais do homem, debruçando-se sobre as produções (artísticas ou não) da sensibilidade, com o fim de determinar suas relações com o conhecimento, a razão e a ética." (ROSENFIELD, 2009, p.7). Também, entende-se que a estética denota a capacidade do homem e sentir e perceber a si próprio e ao mundo num todo integrado, inspirando e conduzindo as percepções e as sensações para dentro de si (DUARTE Jr., 2004).

No âmbito dos serviços, a estética é uma das dimensões da qualidade propostas por Garvin (1987), muito embora o autor proponha uma definição ambígua, a qual dificulta sua operacionalização no âmbito do Design. No caso de serviços em hospitais, objeto de estudo desta pesquisa, uma questão crítica em termos de estética é, seguindo outra dimensão proposta por Garvin (1987), a "conformidade" (nível de atendimento a padrões previamente especificados). Aqui, a integração destas duas dimensões é tratada como "consistência estética". A importância da consistência estética para os serviços públicos é salientada em estudos. Fadel \& Filho (2009) identificou que a tranquilidade ao utilizar os serviços e a clareza ao esclarecer dúvidas foram fatores críticos na percepção de qualidade (90\%). Na pesquisa de Cerchiaro (2006, p. 103), as conclusões apontam para deficiências estéticas na relação entre indivíduos, em categorias que indicam cuidado ("nem me olhou", "cuidou bem do meu pai porque já o conhecia"), sempre em primeiro lugar, antes mesmo das referências às instalações físicas, limpeza, médicos e enfermeiros, etc.

No âmbito dos artefatos, a avaliação estética apresenta base teórica e conceitual e ferramentas de apoio ao PDP (SANTOS, 2009). No âmbito do 'D.S', há demanda por maior compreensão e desenvolvimento de ferramentas específicas. $O$ presente artigo propõe um protocolo de avaliação estética capaz de auxiliar aqueles envolvidos no processo de 'D.S'. Sua contribuição é de caráter metodológico, na medida que a maioria das avaliações de serviço que contemplam a questão estética 
adotam abordagens qualitativas descritiva, destacando-se o método SERVQUAL (PARASURAMAN et. al. 1991). Integra-se no protocolo proposto, ferramentas oriundas do 'D.S', permitindo estratégias empáticas e de natureza qualitativa no processo de avaliação estética. O problema central desta pesquisa é consubstanciado na questão: como manter a consistência estética em serviços prestados aos cidadãos? Desta forma, o objetivo é propor um protocolo de avaliação estética, capaz de auxiliar a manutenção da consistência estética em serviços prestados aos cidadãos.

\section{AVALIAÇÃO ESTÉTICA E ESTÉTICA DE SERVIÇOS}

A experiência estética em serviços tem natureza multidimensional (LIU, 2003; CANDI, 2008). Enquanto no design de produtos tal avaliação pode ater-se a relação usuário $x$ artefato, no 'D.S' a percepção estética ocorre com múltiplos artefatos, múltiplos pontos de contato, de forma simultânea ou não. A percepção estética ao longo da jornada da experiência do usuário não pode ser tratada como a 'soma' das experiências estéticas. De fato, a percepção estética de um dado artefato será influenciada pela percepção advinda da etapa anterior da jornada do usuário (e sua expectativa quando à etapa posterior). Ainda, outros dois elementos compõem esta avaliação estética: a percepção da relação com as pessoas envolvidas no provimento do serviço e a percepção da organização como um todo (ex: brand, imagem), conforme postula Lehtinen \& Lehtinen (1982). Esta natureza social de (parte) dos pontos de contato dos serviços é relevante para a estética, na medida em que o propósito, a motivação e a habilidade de interagir com as pessoas pode determinar a qualidade da experiência do usuário (CZEPIEL, 1990). A importância dessa dimensão na experiência do serviço pode variar de acordo com a natureza do serviço e da participação dos artefatos no provimento da satisfação ao usuário final (SOLOMON et. al. 1985).

Para efetivar a análise da estética em serviços em suas principais relações (relação usuário-produto; usuário-provedor do serviço; usuário-organização), utilizouse as proposições de Norman (2008). Segundo o autor, as emoções e os comportamento do ser humano são resultado de 3 diferentes níveis de estruturas do cérebro: visceral, comportamental e reflexivo. Entende-se que o mundo é primeiramente conhecido mediante os sentidos, daí a relevância do modelo de Norman (2008) para os propósitos desta pesquisa. São os sentidos os responsáveis por colocar o homem em contato com a realidade. Este conhecimento necessita ser processado por um outro nível: o comportamental. Quando se toma ciência dos conhecimentos que os sentidos proporcionam, o homem consegue modificar seu comportamento e tem a possibilidade de seguir para o próximo patamar: a dimensão do reflexivo. Consciente acerca dos conhecimentos que os sentidos oferecem e das modificações operadas no comportamento, o homem simboliza o mundo de maneira profunda e abrangente.

Há várias proposições de avaliação da qualidade dos serviços, sendo que a maioria destes critérios tem relação direta ou indireta com a estética dos serviços. Löwgren (2009 apud CHO, 2013), apresenta o conceito de interação estética em serviços de acordo com quarto conceitos: Pliability (o sentido de maleabilidade); Ritmo (da interação); Estrutura dramática (tensão dramática ao longo do tempo) e Fluência (a elegância com que se realiza múltiplas tarefas). Outros conceitos incluem prazer, diversão (BLYTHE, et. al. 2005), surpresa, encantamento (MCCARTHY \& WRIGHT, 
2003). O modelo SERVQUAL adota cinco dimensões para avaliar a qualidade de um serviço: tangíveis, confiabilidade, presteza, responsividade e empatia, incluindo desta forma tanto os aspectos tangíveis como intangíveis dos serviços (PARASURAMAN et. al. 1988; MANGOLD \& BABAKUS, 1991). Nos aspectos intangíveis destaca-se a 'empatia', ou seja, a atenção individualizada que a organização dá ao usuário, assim como a motivação dos funcionários do provedor do serviço em gerar confiança e segurança no cliente. Cho (2013) inclui na lista de critérios de qualidade de um serviço: respeito, consideração, contato amigável, credibilidade, educação.

\subsection{Procedimentos Metodológicos}

A presente pesquisa é de natureza qualitativa, uma vez que há uma relação dinâmica entre o mundo real e o sujeito que não pode ser traduzida em números (SILVA; MENEZES, 2005). Quanto aos seus objetivos, caracteriza-se como exploratória, pois visa a proporcionar maior familiaridade com o problema para torná-lo explícito. Tem como procedimentos técnicos a revisão bibliográfica sistemática (RBS) e um estudo de caso de caráter etnográfico. Dentro de uma lógica abdutiva, característica da Design Science, a pesquisa propôs o seguinte protocolo para a avaliação estética:

Quadro 1 - Estrutura Geral do Protocolo de Avaliação Estética

\begin{tabular}{|l|l|}
\hline Etapa & Ferramentas \\
\hline Etapa I: Preparação & $\begin{array}{l}\text { Desktop Research, Revisão Bibliográfica sistemática (RBS), Análise } \\
\text { Documental, Filmagens, Fotografias, Shadowing e Personas. }\end{array}$ \\
\hline $\begin{array}{l}\text { Etapa II: Caracterização da } \\
\text { percepção estética do Serviço }\end{array}$ & $\begin{array}{l}\text { Dimensão Visceral: Survey de Percepção Estética Visceral; } \\
\text { Dimensão Comportamental: Jornada do usuário; Matriz de Pontos } \\
\text { de Contato e Blueprint. } \\
\text { Dimensão Reflexiva: Focus Group e Card-sorting. }\end{array}$ \\
\hline Etapa III: Análise das informações & Benchmarking; brainstorming; Storyboard; Crowd-voting. \\
\hline
\end{tabular}

Fonte: Elaborado pelos autores, com base na pesquisa realizada.

A RBS delimitou um panorama das produções científicas na área. Foram realizados: 1) Pesquisa no Banco de Teses da CAPES, com a utilização do termo 'Design de Serviços'. Foram encontradas 1 tese e 7 dissertações. 2) Pesquisa no banco de teses e dissertações da ProQuest, com a utilização do termo 'Service Design'e 63 trabalhos foram selecionados. 3) Pesquisa em periódicos e livros científicos. 4) Pesquisa no Portal de Periódicos Capes/MEC com palavra-chave 'Service Design' e idioma 'inglês', 40 artigos foram selecionados. O próximo passo contou com a utilização de ferramentas de cunho etnográfico, pois os dados coletados envolviam pessoas que utilizavam um serviço. Foram utilizadas as ferramentas: desktop research, análise documental, filmagens, fotografias, shadowing e personas. No âmbito da dimensão estética, foram utilizadas survey de percepção estética visceral, com a utilização da ferramenta 'roda de emoções' para mapear as emoções viscerais suscitadas pelo 
servicescape ${ }^{1}$ do HIZA nos usuários. Somente a visão, a audição, o olfato e o tato foram mapeados. Por recomendação médica e pelas restrições presentes no servicescape, o paladar não foi mapeado. Para mensurar a dimensão comportamental, utilizou-se: jornada do usuário; matriz de pontos de contato e blueprint. Para mensurar a dimensão reflexiva, utilizou-se o grupo focal e o card-sorting.

\subsection{Resultados e Análise}

\subsubsection{Contexto do Estudo de Caso}

O estudo de campo desta pesquisa foi realizado no 'Hospital do Idoso Zilda Arns' - HIZA, o qual disponibiliza 131 leitos, um centro cirúrgico e atende a 17 especialidades médicas. O modelo de atendimento adotado pelo HIZA está voltado para a humanização do cuidado e a observação das normas internacionais de qualidade e segurança do paciente.

A presente pesquisa teve como delimitação para a avaliação estética uma área de recepção ao idoso, a recepção 01 (Figura 01). Em paralelo, foi elaborado um mapa do sistema com o propósito de situar o HIZA dentro do sistema no qual ele está inserido e compreender quem são e onde estão os demais stakeholders (Figura 02).

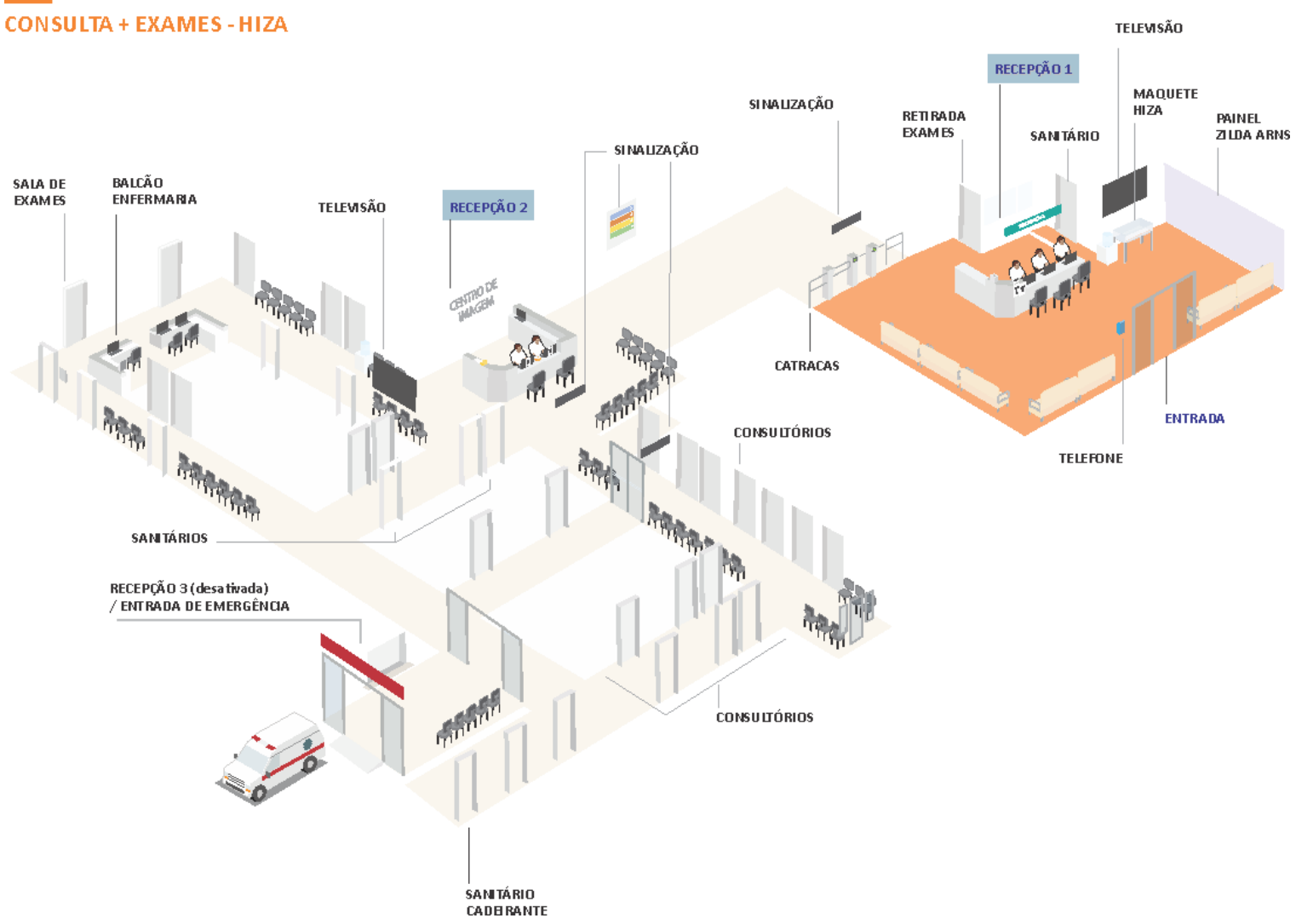

Figura 01: Planta alta do piso térreo do HIZA com destaque para a Recepção 01. Fonte: Elaborado pelos autores, com base nos dados fornecidos pelo HIZA.

1 Termo refere-se ao ambiente criado, construído e planejado para intermediar as interações entre empresa e cliente (BERRY et. al. 1990). 


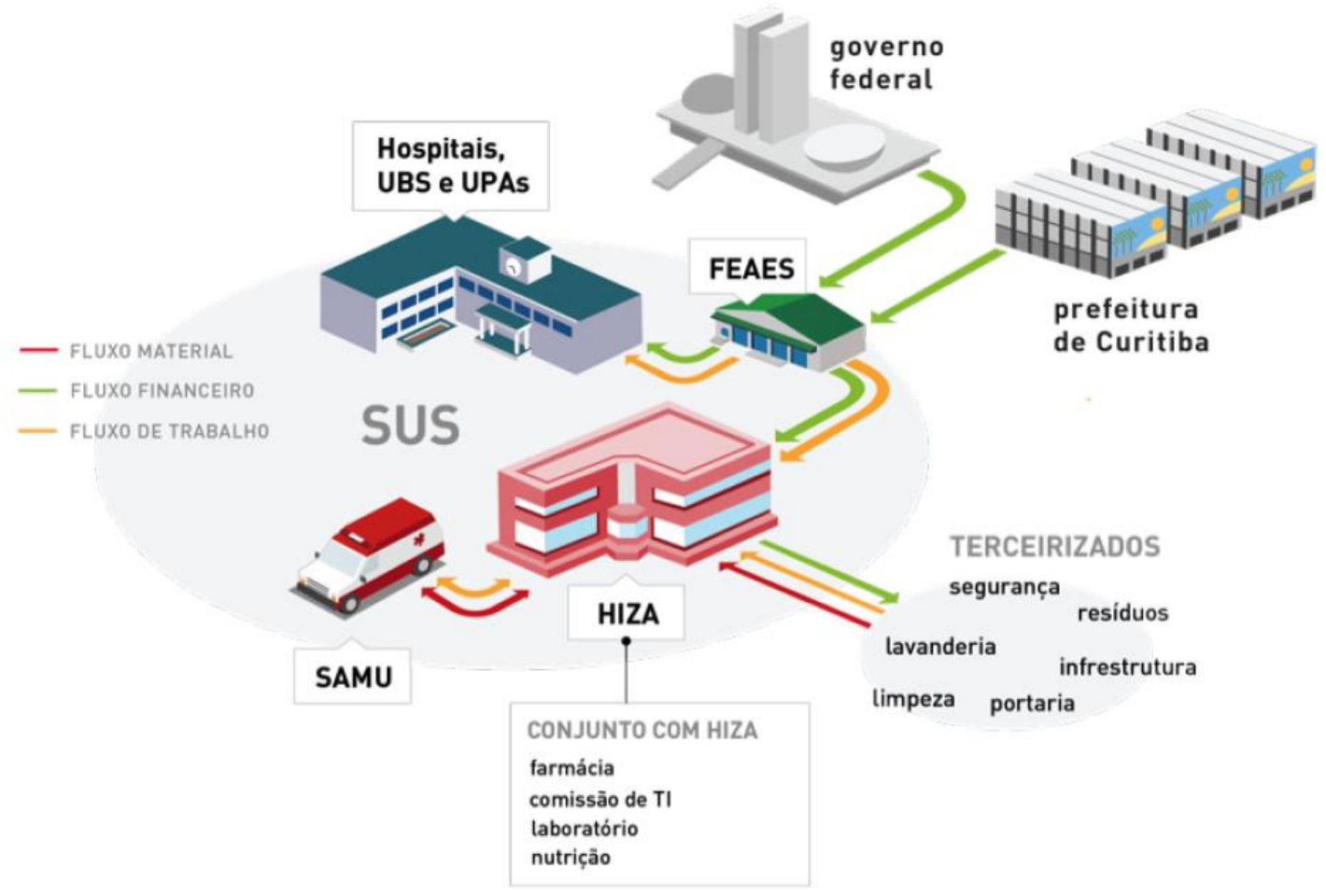

Figura 02: Mapa do Sistema situando o HIZA dentro do sistema e os demais stakeholders Fonte: Elaborado pelos autores, com base na pesquisa realizada.

\subsubsection{Etapa I: Preparação}

Os dados obtidos, coletados no desktop research e na análise documental, mostraram que a maioria dos atendimentos são referentes a consultas e exames, seguidos de internamentos e atendimentos emergenciais. Os dados também mostraram que: 1) a idade média do público atendido varia de 45 a 72 anos; 2) o nível de instrução dos pacientes é baixo: Ensino Fundamental/Médio: 42,7\%; analfabetos: 5,7\%; pacientes com diploma: $2,9 \%$ e $44 \%$ dos pacientes não informaram o grau de escolarização; 3 ) os óbitos ocorrem mais nos setores de internação emergencial, com $24 \%$ e $11 \%$. Concluiu-se que o público alvo deveria englobar os pacientes que recorrem ao HIZA para fazerem exames ou consultas, com idades entre 45 e 70 anos. Os dados obtidos no desktop research, as filmagens e as fotografias, possibilitaram a geração de 4 personas que englobam todos os usuários que são atendidos pelo HIZA e foi possível estabelecer o roteiro para o shadowing. As personas e as filmagens permitiram o alinhamento das informações, o que possibilitou o direcionamento para o sentido dos usuários no contexto envolvido e orientou a coleta dos dados nas próximas etapas. Baseado nas personas, o shadowing permitiu compreender como os usuários se relacionavam com o contexto do serviço.

\subsubsection{Etapa II: Caracterização da Percepção Estética - Visceral, Comportamental e Reflexiva}

Segundo Norman (2008, p. 42), o nível visceral das emoções e comportamento humano é o responsável por "fazer julgamentos rápidos, como o que é bom ou ruim, 
seguro ou perigoso." Diz respeito aos aspectos físicos e ao impacto emocional imediato causado por um produto ou serviço e circunscreve-se às suas características, as quais estimulam os sentidos com resposta imediata. A aparência, o cheiro, o toque e o som predominam e são determinantes no resultado da experiência. A avaliação da percepção estética visceral baseou-se na lógica analítica da ferramenta SERVQUAL. Essa ferramenta está baseada em 5 GAPs e é dividida em dois hemisférios: o "hemisfério do cliente" e o "hemisfério da empresa" prestadora do serviço (BERRY et. al. 1990). A survey realizada acerca da dimensão visceral utilizou a 'roda de emoções', que mapeia as emoções viscerais que os usuários relataram ao sentir ao utilizar o serviço. Ao todo, 977 usuários foram consultados, gerando 400 rodas válidas. A Figura 03 ilustra uma das ferramentas utilizadas na survey.

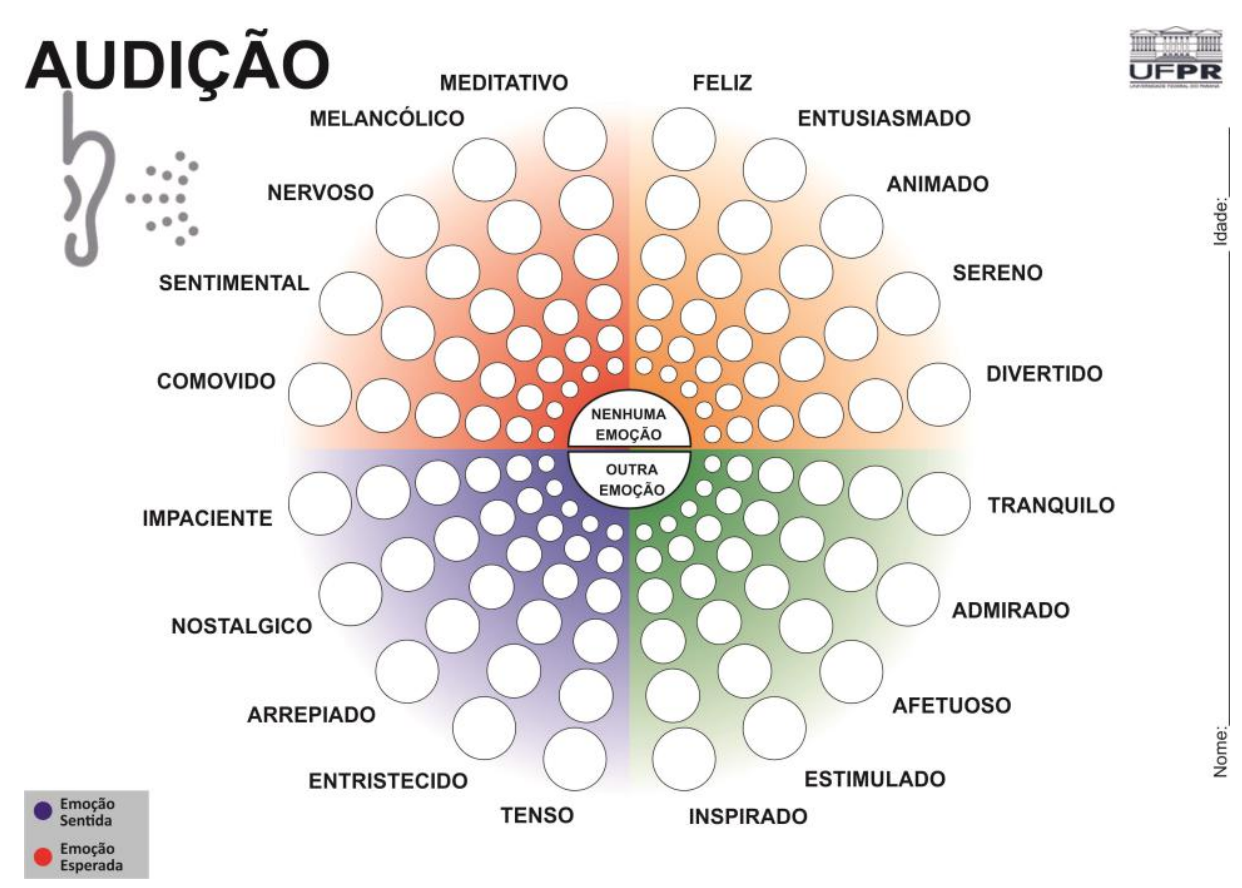

Figura 03: Exemplo de ferramenta utilizada para avaliar a dimensão visceral da estética no serviço. Fonte: Elaborado pelos autores, com base na pesquisa realizada.

Para a elaboração das ferramentas de coleta de dados, investigou-se uma gama diversificada de ferramentas que podem ser usadas para elicitar e mensurar as emoções que são suscitadas ao se interagir com um produto ou uma interface WEB, como a Escala Estética, a Grade Afetiva, o Diário Afetivo, a AttrakDiff, a Geneva Emotion Wheel, a PREMO, etc. (ALL ABOUT UX, 2015).

A dimensão comportamental, segundo Norman (2008, p. 14), está relacionada com os "processos cerebrais que controlam a maior parte das ações" do homem, tais como "andar de bicicleta, tocar um instrumento musical, dirigir um carro", etc. Circunscreve-se ao uso do produto/serviço do ponto de vista objetivo e refere-se à função que o produto/serviço desempenha, à facilidade com que o usuário o compreende e o opera, à eficácia com que cumpre sua função e aos demais fatores relacionados com o modo de o usuário se comportar junto ao produto/serviço. A análise da estética sob o ponto de vista da dimensão comportamental centrou-se na 
compreensão do fluxo da experiência do usuário do HIZA. Assim, foi elaborada uma jornada do usuário, uma matriz de ponto de contato e, subsequentemente, foi produzido um blueprint de todo o serviço. Precedendo a elaboração da jornada, foram coletadas fotografias de todo o trajeto dos usuários, produzido uma matriz dos pontos de contato. A aplicação da matriz de ponto de contato e da técnica do shadowing permitiu compreender os aspectos mais relevantes nesta jornada (Figura 04), evidenciando o exato momento, no qual eventuais erros aconteciam, expressões faciais dos usuários, comentários verbais, direcionamento do olhar. Estar imerso na execução do serviço revelou-se uma maneira eficaz para desenvolver uma compreensão abrangente do mesmo, além de possibilitar um entendimento íntimo das interações em tempo real, interações estas que aconteceram entre os vários atores do processo e destes com os pontos de contato disponíveis.

Somente os usuários que se enquadravam dentro do perfil das personas foram envolvidos no processo de elaboração da jornada. A Figura 05 mostra os trajetos das personas no HIZA. Note que a persona 01 e a persona 03 chegam ao hospital e entram pela entrada principal. Elas possivelmente chegaram de ônibus ou, se de carro, este parara em outro lugar e elas tiveram de caminhar para terem acesso ao hospital, pois neste não há estacionamento, tampouco lugar para desembarque, uma vez que esta entrada está em uma via de alto tráfego. A persona 1 foi ao hospital para fazer um exame, enquanto a persona 3 ali estava para uma consulta com médico especialista. Ambas as personas entraram e saíram do HIZA pelo mesmo acesso. A pernona 2 chegou de carro ao hospital, sendo conduzida por um familiar. O carro ficou parado no estacionamento do HIZA. No entanto, a persona 2 necessitara de internamento e foi acomodada na enfermaria. A persona 4 chegou ao HIZA de ambulância. Como estava necessitando de atendimento emergencial, esta fora levada primeiramente para a 'sala de estabilização', depois foi para a 'sala de observação' e, por fim, obedecendo a ordens do médico, foi internada no HIZA, sendo acomodada na sua Enfermaria. Com o blueprint (Figura 06) foram mapeados os diferentes elementos visíveis e/ou físicos com os quais o usuário interage, isto é, contém todas as ações do usuário e toda a sua interação com hospital, desde as operações visíveis até aquelas que ocorrem no backstage. Buscou-se descrever as evidências físicas, os diferentes atores com suas ações ao longo da jornada, o que permitiu a identificação de pontos falhos e superposições desnecessárias para melhoria da qualidade estética do serviço. Uma vez elaborado, ao analisar as colunas do blueprint, pode-se compreender as experiências e ações dos diferentes atores envolvidos. Já a leitura horizontal leva-se à compreensão da integração dos diversos elementos do processo de prestação do serviço. 


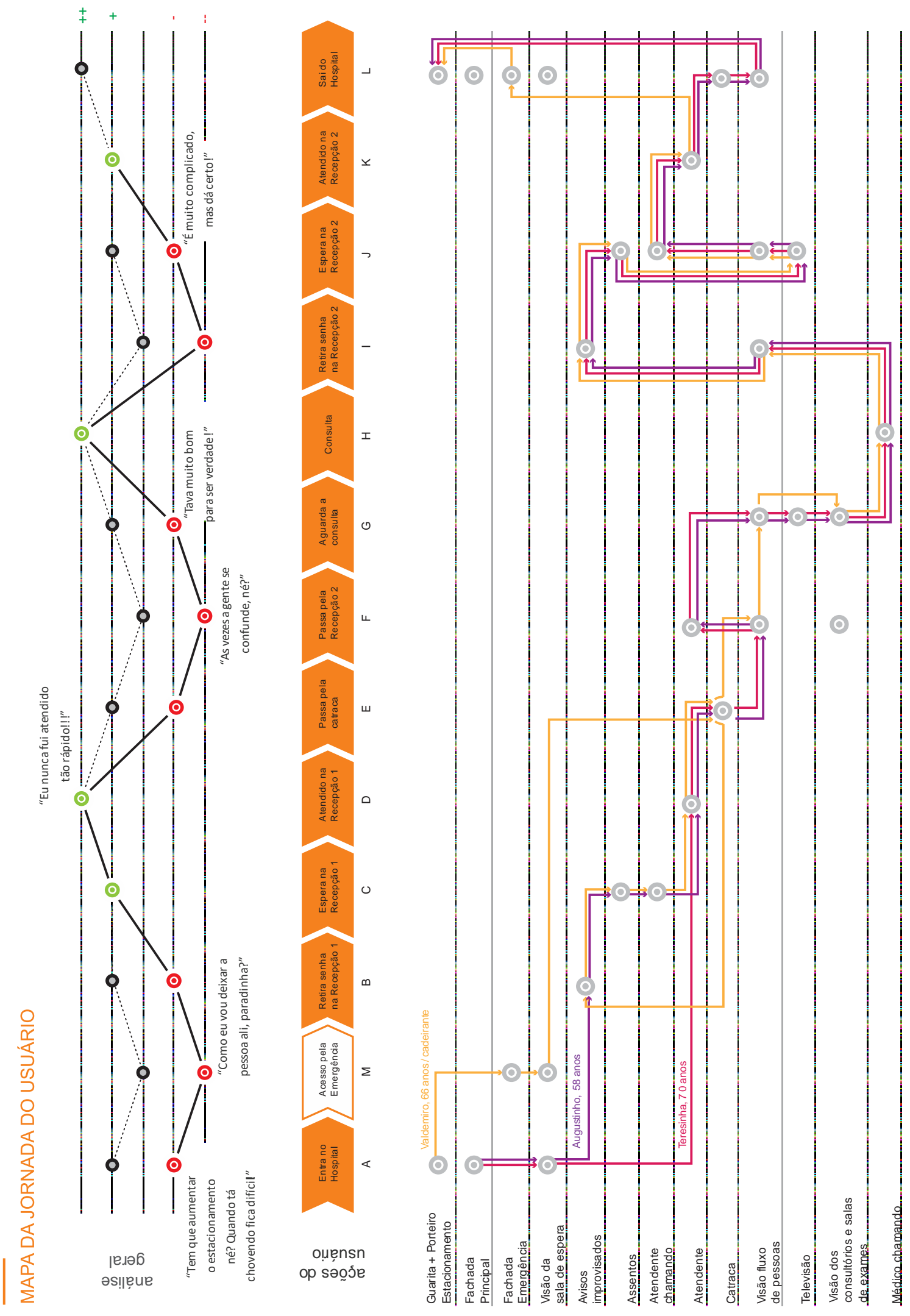

Figura 04: Mapa da jornada que o usuário realiza ao utilizar os serviços do HIZA.

Fonte: Elaborado pelos autores, com base na pesquisa realizada. 


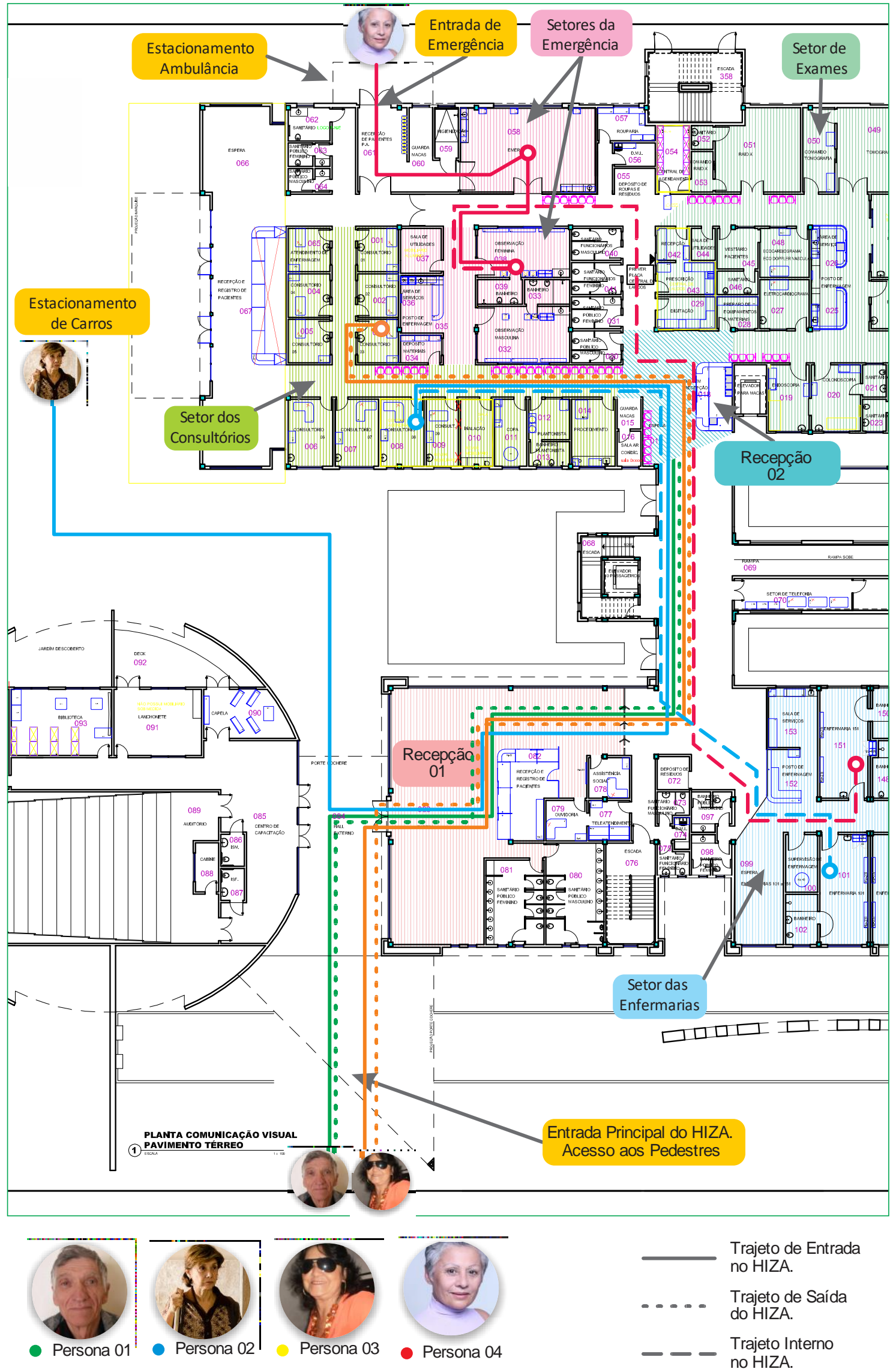

Figura 05: 0 trajeto realizado pelos usuários no HIZA captado pelo Shadowing.

Fonte: Elaborado pelos autores, com base na pesquisa realizada. 


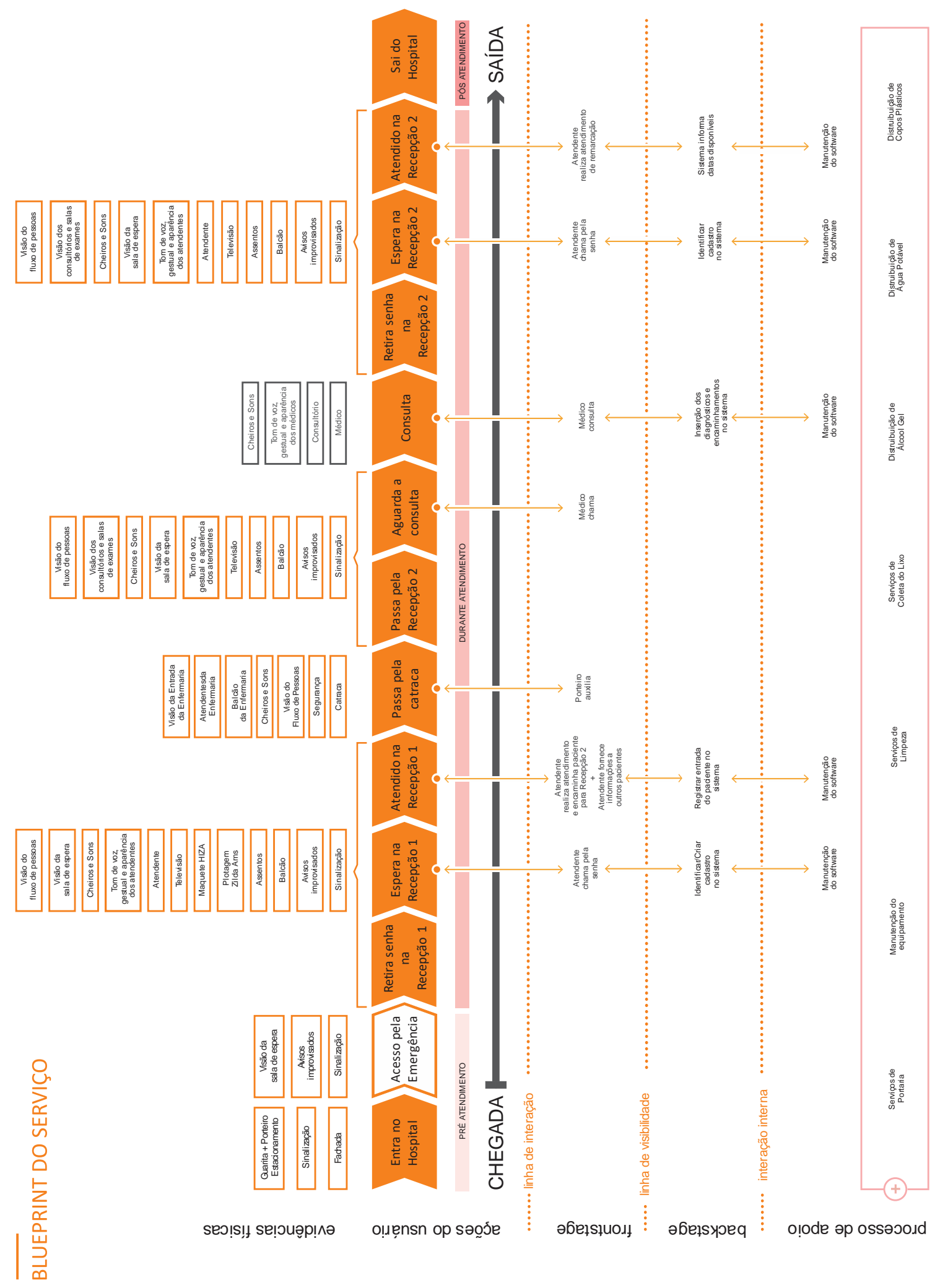

Figura 06: Blueprint do serviço oferecido pelo HIZA.

Fonte: Elaborado pelos autores, com base na pesquisa realizada.

A dimensão reflexiva refere-se "à interpretação, compreensão e raciocínio e à parte contemplativa do cérebro". Nesse nível "são processadas ações como apreciar uma obra de arte, sentir saudade de um amigo, torcer para um time de futebol", etc. 
(Norman, 2008, p.14). Trata-se da ótica subjetiva e abarca as particularidades culturais e individuais, a memória afetiva e os significados atribuídos aos produtos, aos serviços e ao seu uso, dentre outros aspectos (Norman, 2008).

Com o propósito de mapear o âmbito reflexivo das emoções suscitadas pelo servicescape do HIZA e tendo como base os dados levantados nas etapas anteriores, especialmente os dados originários da 'roda de emoções', realizou-se um grupo focal com a utilização de card-sorting, contando com 8 participantes (4 pacientes e 4 funcionários do HIZA - 1 médico, 1 enfermeiro e 2 atendentes da recepção). Por meio dos dados coletados, pode-se perceber que as opiniões dos participantes eram compartilhadas. Tais resultados evidenciaram a confusão gerada nos pacientes na recepção 01, as dificuldades dos pacientes que visitam o HIZA pela primeira vez, a dificuldade de retirar senha, a falta de informação visual e a dificuldade para os embarque e desembarque, especialmente com relação aos cadeirantes. Ainda, descobriu-se que a tecnologia é fundamental, porém o carinho e a atenção para com os pacientes são insubstituíveis. Acerca da rapidez no atendimento, ficou evidente que os idosos, bem como os acompanhantes, não gostam de esperar, considerando qualquer demora como perda de tempo.

\section{CONCLUSÃO}

Em caráter preliminar, a presente pesquisa apresentou um protocolo para avaliação estética de serviços. Tal protocolo é composto por três etapas e utiliza ferramentas oriundas do contexto do 'D.S'. O protocolo proposto é de fácil aplicação, pois utiliza ferramentas empáticas e possui uma estrutura flexível. Tal estrutura, dependendo da complexidade/simplicidade do serviço a ser analisado, pode sofrer alterações. As 'Etapas' podem ser divididas em sub-etapas. No entanto, recomenta-se manter a estrutura mínima, composta pelas três etapas descritas. Com relação às ferramentas utilizadas em cada etapa, estas podem ser trocadas ou descartadas e outras ferramentas podem ser adicionadas, dependendo da necessidade do profissional. Todavia, ressalta-se que o protocolo proposto trata-se de uma primeira versão, é faz parte de uma pesquisa que está sendo desenvolvida no programa de doutoramento em Design e que ainda passa por um processo de refinamento. Assim, é compreensível que tal protocolo sofra alterações. Ao apresentar os dados da pesquisa neste artigo, espera-se que o mesmo, além de estimular e provocar o debate e a reflexão acerca da temática tratada, gere feedbacks que possam contribuir para a melhoria da pesquisa e para o avanço dos estudos no âmbito do 'D.S.'. As contribuições podem ser enviadas por e-mail aos autores deste trabalho.

\section{REFERÊNCIAS}

ALL ABOUT UX. Disponível na internet por http em: < http://www.allaboutux.org/>. Acesso em 12 dez. 2015.

BERRY et. al. Five Imperative for Improving Service Quality. 1990. Disponível na internet por http em: <http://areas.k/Mkt/zeithaml.pdf>. Acesso em 19 dez. 2015.

BLYTHE, Alan et. al. Funology. Dordrecht: kluwer Academic Publishers, 2005. 
CANDI, Marina. Aesthetic Design as an Element of Service Innovation in New Technology-based Firms. 2008. Disponível na internet por http em: <http://openarchive.cbs.dka_candi.pdf>. Acesso em 19 dez. 2015.

CANDI, Marina; SAEMUNDSSON, Rögnvaldur. Exploring the Relationship Between Aesthetic Design as an Element of New Service Development and Performance. 2011. Disponível na internet por http em: <http://lib.com/10.pdf>. Acesso em 19 dez. 2015.

CERCHIARO, Isabel B. Qualidade de serviços no setor público brasileiro: uma abordagem feminista. 2006. 133 f. Tese (doutorado) - Fundação Getúlio, Curso de Pósgraduação em Administração.

CZEPIEL, John A. Service Encounters and Service Relationships. Disponível na internet por http em: <http://www.sd/article>. Acesso em 19 dez. 2015.

DUARTE Jr., João F. O Sentido dos Sentidos. 3.ed. Curitiba: Criar, 2004.

FADEL, Marianella A. V.; REGIS FILHO, Gilsée I. Percepção da qualidade em serviços públicos de saúde. 2009. Disponível na internet por http em: <http://www.scielo.br/pdf/rap/v43n1/a02v43n1.pdf>. Acesso em 09 dez. 2015.

FREIRE, Karine de Mello. Design de Serviços, Comunicação e Inovação Social. 2011. 254 f. Tese (Doutorado) - Pontifícia Universidade Católica do Rio de Janeiro, Curso de Pós-graduação em Artes e Design.

Garvin, David. Competiny on the Eight Dimensions of Quality. 1987. Disponível na internet por http em: <http://www.hbs.edu/faculty=11440>. Acesso em 09 dez. 2015.

IBGE. Pesquisa anual de serviços. Vol.1. Rio de Janeiro: IBGE, 2010.

LEHTINEN, Ulla. LEHTINEN, Jarmo R. Service Quality: A Study of Quality Dimensions. Unpublished working paper. Helsinki: Service Management Institute, 1982.

LIU, Yili. Engineering aesthetics and aesthetic ergonomics: Theoretical foundations and a dual-process research methodology. Ergonomics, 2003, v.46, n. 13, p.1273-1292.

MANGOLD, Glynn; BABAKUS, Emin. Service Quality: the Front-stage vs. the Back-stage Perspective. 1991. Journal of Services Marketing, v. 5 n.4, pp. 59-70.

MCCARTHY, John; WRIGHT, Peter. Tecnology as Experience. 2003. Disponível na internet por http em: < http://www-ist.m.ac.nz/plyons.pdf>. Acesso em 19 dez. 2015.

NORMAN, Donald A. Design Emocional. Rio de Janeiro: Rocco, 2008.

OLIVEIRA Jr. Carlos Eduardo. Serviços: PIB e Segmentação. Disponível em: <http://www.cnservicos.org.br/doc/PIB_Segmentacao.pdf>. Acesso em 08 jan. 2015.

PARASURAMAN, Arun et. al. Servqual: a multiple item scale for measuring consumer perceptions of service quality. Journal of Retailing, St. Louis, v. 64, n.1, p.12-40, 1988.

et. al. Refinement and Reassessment of the SERVQUAL Scale. 1991.

Disponível na internet por http em: <http://areas.kenan/Mkt.pdf>. Acesso em 08 jan. 2015.

PINHANEZ, Claudio. Services as Customer-Intensive Systems. Design Issues, v. 25, n. 2, 2009, p. 3-13.

Rosenfield, Katharin. Estética. Rio de Janeiro: Jorge Zahar, 2009. 
SANTOS, Aguinaldo dos et. al. Assessing the use of Product-Service Systems as a strategy to foster sustainability in an emerging context. 2014. Product (IGDP), v. 12, p. 99-113, 2014.

SANTOS, Aguinaldo dos; COSTA, Humberto. Diálogo entre pós-graduação e graduação: a introdução do ensino do design de sistemas produto+serviço na UFPR. Projética, v. 5, p. 243-255, 2014.

SANTOS, Célio T. dos. Requisitos de linguagem do produto: uma proposta de estruturação para as fases iniciais do PDP. 2009. 205 f. Tese (doutorado) - Universidade Federal de Santa Catarina, Programa de Pós-Graduação em Engenharia Mecânica.

SOLOMON, Michael et. al. A role theory perspective on dyadic interactions. 1985. Disponível na internet por http em: <http://www.ida.83.pdf>. Acesso em 08 jan. 2015. 